\title{
El movimiento anulista en 2009 y la abstención \\ Los signos de las elecciones de los primeros años del siglo XXI en México
}

En los comicios del año 2000 el llamado "voto útil" fue necesario para que la oposición venciera al PRI en la elección presidencial. Las elecciones de 2003 se destacaron por una alta abstención. Los comicios de 2006 estuvieron marcados

Se describe y analiza el movimiento por el voto nulo que surgió en la coyuntura de las elecciones federales de 2009. Se rastrean los primeros signos de la emergencia de este novedoso movimiento: cómo se promovió el voto nulo; el rechazo que suscitó en partidos, organismos electorales y jerarquía católica; el debate que se dio a nivel nacional en torno a este movimiento; las formas organizativas que

fue adoptando dicho movimiento y los impactos que tuvo. Se tiene como telón de fondo el incremento de la abstención y sus implicaciones.

Palabras clave: voto nulo, elecciones, abstención, partidos políticos, movimiento.

Profesor-investigador del CIESAS-Occidente y de la Universidad de Guadalajara.

jalonso@ciesas.edu.mx. por la campaña sucia del gobierno, su partido y las cúpulas empresariales en contra de un candidato opositor y por la grave polarización que esto produjo. En 2009 lo que llamó la atención en el proceso electoral fue que surgió un polimorfo movimiento que llamó a ejercer el voto nulo.

\section{Indicios de una creciente} abstención y de un voto nulo consciente

A mediados de febrero de 2009 varios articulistas y encuestadores empezaron a dar una voz de alerta. El analista José Antonio Crespo resaltó que las condiciones políticas prevalecientes no incitaban a votar. Recordó que había 30\% de electores que nunca acudía a las urnas. Además entre los que sí votaban, 
existían los que pensaban que ahora los partidos no se diferenciaban sustancialmente, y se habían decepcionado de todos. También se había perdido la confianza en las autoridades electorales (Crespo, 2009a). El académico Miguel Bazdresch apuntaba que muchos ciudadanos cuestionaban el acto de votar debido a una creciente indignación contra los políticos y gobernantes. No estaban de acuerdo con las enormes cantidades de dinero que desperdiciaban los partidos cuando había tantas necesidades colectivas (Bazdresch, 2009). Crecía el número de los que confesaban que no votarían, el cual se estimaba en $65 \% .{ }^{1}$ Quienes no creían en los mensajes de los partidos y candidatos alcanzaban $73 \% .^{2}$ El Centro de Estudios Sociales y de Opinión Pública de la Cámara de Diputados consideraba que siete de cada 10 ciudadanos podían abstenerse o anular su voto. ${ }^{3}$ A finales de mayo había encuestas que apuntaban que el voto nulo podría alcanzar $10 \% .{ }^{4}$ El panista Felipe Vicencio reconocía que las condiciones políticas no eran las más propicias para incentivar la participación electoral, por el alejamiento de los partidos de las aspiraciones de la sociedad. Puntualizó que la postura abstencionista era compleja, pues iba desde el desinterés hasta la hiperpolitización. Los promotores de la anulación del voto enfrentaban la dificultad de que el sistema electoral empañaba la visibilidad de las cifras que no fueran las de los votos partidistas (Vicencio, 2009). Se detectaba que estaba en marcha un incipiente movimiento de promoción del voto nulo, y surgían dudas acerca de qué ganaría el voto nulo si no tenía más propuestas que el rechazo. Los promotores del voto nulo fueron respondiendo con planteamientos de quehaceres futuros. 


\section{La promoción del voto nulo}

Muy al inicio de las campañas electorales de 2009 en diversos portales y blogs de Internet se convocaba a anular el voto o a abstenerse. Mientras el IFE intensificaba una campaña de promoción del voto, otros grupos usaban la red para incitar a que el voto anulado dijera más pues los partidos necesitaban el voto, pero usurpaban los derechos ciudadanos. Se discutía si lo conveniente era votar por el menos malo, al azar, o por ninguno. Se enfatizaba que en el sistema mexicano no había la opción del voto en blanco como en otros países donde existe un recuadro para manifestar un voto por ninguno. Se debatía si la abstención o el voto nulo podían presionar a la clase política. Se aclaraba que el voto nulo consciente no correspondía a actitudes de apatía sino al rechazo activo. En muchos de esos sitios se manifestaba que habría que presionar a los partidos para que realizaran reformas con vistas a una auténtica democratización. Había un grupo que había optado por el nombre Yo anularé mi voto. Destacaba el grupo que se identificaba con el lema Para políticos nulos, un voto nulo. Había analistas políticos que insistían en que el voto por ninguno era una muestra más fuerte de inconformidad (Crespo, 2009b).

La mayor promoción del voto nulo se hizo en la red electrónica. En Facebook se encontraron 250 grupos que llamaban a anular el voto. También se utilizó Twitter y You Tube (Islas, 2009). En sus respectivos portales, difundieron diversos boletines. A finales de mayo, uno de estos grupos resaltaba que su campaña por la anulación del voto correspondía a la iniciativa de varios ciudadanos que estaban inconformes con el sistema político prevaleciente. Esos ciudadanos invitaban a acudir a las urnas, y si ningún candidato convencía, exhortaban a que se ejerciera el derecho de anular el voto. Había espacios en donde se mostraba cómo se podía hacer eso en concreto ya tachando 
toda la boleta, ya poniendo en ella algún mensaje para la clase política o combinando ambas cosas. Explicaban que la anulación intencional del voto se debía a que los partidos se habían envilecido cada vez más en los últimos años porque habían sido asaltados por poderosos grupos económicos y religiosos. Otra razón tenía que ver con el hecho de que los partidos habían desdibujado su perfil ideológico. Además, los candidatos de los diversos partidos, una vez que asumían sus puestos públicos, respondían a los grupos de poder y no a los intereses ciudadanos. Un argumento más para optar por la anulación del voto era porque los procesos electorales se habían convertido en circos mediáticos. Los promotores del anulismo enfatizaban que abstencionistas y anulistas conformaban una inmensa mayoría. Subrayaban que la anulación del voto se había convertido en un medio para la construcción de la democracia verdadera. Argüían que la legislación electoral se había diseñado y se utilizaba para servir a los partidos y no a los ciudadanos, pues tenía muchos candados partidistas que entorpecían el funcionamiento de una real democracia. En Jalisco los anulistas no estaban de acuerdo con el presidente del organismo electoral local, quien afirmó que el voto por candidatos independientes era una herencia del pasado sin valor político ni jurídico. Demandaban que los partidos y los organismos electorales organizaran un debate público con todos los actores para que se pudiera deliberar en torno a un nuevo ordenamiento que propiciara efectivamente una participación ciudadana que incidiera en la toma de decisiones y la gestión de lo público. ${ }^{5}$ Un grupo jalisciense imprimió calcomanías que distribuyó con su lema "Para políticos nulos, votos nulos", y organizó acciones de difusión como proyecciones rápidas en paredes de sitios donde se reunían los jóvenes. 


\section{Organizaciones promotoras del voto empiezan a tener en cuenta al voto nulo}

Alianza Cívica se propuso dar seguimiento a la calidad del voto. Se pretendía ver la compra y coacción del voto y monitorear el clientelismo electoral. Alianza Cívica había demandado bajar a la mitad el financiamiento público a los partidos, reducir el número de senadores y diputados, y establecer el derecho de iniciativa legislativa ciudadana. Habría que impedir que los organismos autónomos siguieran siendo botín de reparto de cuotas partidistas. Aconsejaba que se evitara que las televisoras usaran esa protesta ciudadana para revertir la reforma electoral y que regresara la compraventa de publicidad electoral en medios electrónicos (Gómez, 2009). En Jalisco quienes participaban en Alianza Cívica respondieron a los promotores del voto nulo que ellos convocarían a los ciudadanos a acudir a las urnas para que eligieran a los candidatos que consideraran buenos. No obstante, si había ciudadanos a los que no les convencían los candidatos, entonces llamaban a no desperdiciar el voto en el menos malo, sino a que se utilizara la opción del voto nulo. ${ }^{6}$

La activista cívica Clara Jusidman planteó la necesidad de que los ciudadanos contaran con información, y promovió lo que denominó un Congreso con Rostro. Se exigía a los partidos información sobre sus propios candidatos para que el ciudadano supiera por quién podría votar. Se debía saber quiénes eran, qué habían hecho, que proponían, cuál era su origen (familiar, partidista, de vínculos empresariales, etc.). Ante eso el PVEM respondió que no daría ninguna información, y los demás partidos ofrecían una información muy incompleta. Se argumentaba que si los ciudadanos no

6. Entrevista con Rafael Lucero, 16 de mayo de 2009.

Teoría y DEBATE 8 No. 47 
tenían suficiente información, legítimamente podían optar por anular el voto. ${ }^{7}$

En el Comité Conciudadano para la Reforma Electoral se realizó una amplia discusión vía Internet. El consenso fue la enorme preocupación por esclarecer las implicaciones del voto nulo. Hubo también coincidencia en que el llamado a anular era una respuesta al hecho de que muchos ciudadanos no se sentían representados por los partidos políticos. La coincidencia mayor versaba en que los ciudadanos debían votar libremente de manera informada. Se constataba que los partidos ocuparían las curules y se distribuirían el financiamiento público, sin que el voto nulo afectara en nada esos repartos. Se llegó a la conclusión de que el comité debería comprometerse en la discusión para la elaboración de una propuesta de cambios legislativos para que acciones como el voto nulo tuvieran consecuencias directas en la ocupación de curules y en la asignación del presupuesto público partidista. Este Comité también alertó sobre el hecho de que el empresario Alejandro Martí estaba siendo utilizado por los enemigos de la reforma electoral de 2007, pues la organización sobre seguridad que presidía hacía suyas las propuestas de que los candidatos se comprometieran a legislar para devolver a los medios electrónicos el poder vender propaganda electoral (Comité Conciudadano para la Reforma Electoral, 2009).

\section{Llamamientos al voto nulo desde instancias muy diversas}

Había otras organizaciones que llamaban a no votar argumentando que todos los partidos funcionaban igual, que el poder era un botín y no un servicio, que votar era callar, dar un cheque en blanco a los partidos que vivían con muchos privilegios y que no representaban a los ciudadanos sino a 
sí mismos. Votar era avalar todo esto. Habría que hacer de la abstención un movimiento consciente que buscara otra forma de hacer política. ${ }^{8}$ Hasta la organización guerrillera EPR convocó a anular los votos. ${ }^{9}$

En 2009 había aumentado el descontento con la partidocracia y con los gobernantes. Tanto los grupos abstencionistas como los anulistas se componían de un universo muy heterogéneo. Quienes proponían que había que votar planteaban que ambas tendencias dejarían en manos de otros la decisión de la conformación del gobierno. No obstante, los anulistas insistían en que darían una señal a la partidocracia para que se corrigiera (Aziz, 2009a). Se defendía que todas las opciones ante las urnas eran legítimas por la libertad del voto. Se veía también que la promoción del voto nulo no contaba con los recursos ni medios que sí tenía la opción de votar por cualquiera de los ocho partidos que en esa elección federal se disputaban las curules de la Cámara de Diputados (Crespo, 2009c).

\section{Debates sobre el voto nulo}

El debate sobre el voto nulo se fue intensificando. El académico Sergio Aguayo — quien había participado activamente en la fundación de Alianza Cívica en los años noventa- anunció que si los candidatos no lo convencían, anularía su voto escribiendo en la boleta "Esperanza Marchita" (Aguayo, 2009a). José Antonio Crespo destacó que mientras el abstencionismo reflejaba inconformidad, desmovilización y hastío, el voto nulo implicaba deseo de expresarse, de hacer visible la inconformidad y de presionar al sistema de partidos para que se abriera y democratizara (Crespo, 2009d). Otros pedían que no se olvidara todo el

8. La otra HuastecaTotonaca, 20 razones para no votar, mayo de 2009.

9. La Jornada, 17 de junio de 2009. 
contexto, pues había crisis de gobernabilidad, pérdida de legitimidad de las instituciones electorales y de los partidos, además de una grave crisis económica. El movimiento por el voto nulo expresaba una reacción de una parte de la élite intelectual y de un sector de la élite social ante la imposibilidad de hacer rendir cuentas a la clase política. Se trataba de un nuevo movimiento con gran participación juvenil. Se buscaba propinarle un castigo a la clase política. No había que perder de vista el protagonismo - alimentado por los medios electrónicos - de ciertos líderes empresariales. El voto nulo era una alternativa para la sociedad civil progresista, pero habría que cuidar que esa acción no terminara abriendo las puertas a una agresiva derecha (Olvera, 2009). Otra vertiente de discusión se abrió cuando se hicieron comparaciones con lo que había sucedido en las elecciones parlamentarias europeas, donde una gran abstención había favorecido a la derecha (Rodríguez, 2009).

Había quienes mostraban lo heterogéneo de los que promovían el voto nulo, lo que llamaban el "amontonamiento de voces disonantes”. Se decía que siendo la crisis real, el camino elegido era inútil y podía ser utilizado por los poderes fácticos que estaban en contra de la reforma electoral (Sánchez, 2009). El presidente de Alianza Cívica aceptó que la desilusión ciudadana frente a los abusos, los escándalos y la incapacidad del sistema de partidos estaba generando una oleada de protesta que proponía anular el voto. Precisaba que crecía espontáneamente y que carecía de un polo articulador, por lo que se manifestaba con muchas ramificaciones. Sostenía que la ilusión de que las cúpulas partidistas atenderían el reclamo de los votos nulos era ingenua y riesgosa; y que acordar una agenda común entre grupos tan diferentes sería algo muy dificultoso (Gómez, 2009).

El candidato a diputado federal por el PAN Javier Corral escribió que entre los promotores de anular el voto había hombres y mujeres rectos con preocupaciones genuinas 
por el deterioro creciente del sistema de partidos, pero aducía que el voto nulo podría generar más un letargo que un despertar, pues contribuiría a reforzar las burocracias de los partidos y sus sectores duros y que el más beneficiado sería el PRI. Planteaba que pasar del voto respetado al voto representativo no se conseguía con anularlo, pues eran la organización social y la exigencia publica las que producirían mejores resultados (Corral, 2009). El jurista John Ackerman insistió en que el voto nulo no podría ser contabilizado como un voto de protesta debido a la opacidad respecto del contenido de los votos nulos en la legislación electoral. Advirtió que los poderes fácticos estaban apostando a aprovechar el desencanto ciudadano para empujar sus propios intereses. Siendo el descontento ciudadano un hecho, faltaba convertirlo en acción concreta para la renovación política del país (Ackerman, 2009a). Ackerman advirtió que los anulistas de izquierda que buscaban un cambio de raíz a la corrupción y a la desigualdad verían después de las elecciones que sus votos serían utilizados para cambios superficiales o para fortalecer agendas contrarias al interés público (Ackerman, 2009b).

Hubo quienes señalaron que era preciso valorar que detrás del voto nulo había una agenda. Se pretendía democratizar el oligopolio partidista y ciudadanizar el poder frente a la partidocracia. No obstante, entre sus promotores no había consenso en cuanto a lo que se debía exigir que cambiara (Gil, 2009). Se remarcaba que el voto nulo, siendo legítimo y legal implicaba un voto de censura a los partidos que sólo buscan su propio beneficio (Narro, 2009). Se advertía, sin embargo, que si la cifra del voto nulo era la acostumbrada perdería su efecto de protesta. No obstante, ante la situación del arreglo partidista prevaleciente el movimiento por el voto nulo podría ser un paso modesto, inicial, pero implicaba algo novedoso (Meyer, 2009). Se le daba al voto un nuevo sentido pues se usaba como arma 
de rechazo, y la clase política debería entender el malestar ciudadano (Aziz, 2009b).

\section{El malestar ante el voto nulo}

Un hecho que llamó grandemente la atención fue la exagerada reacción de políticos, obispos y autoridades electorales en contra del movimiento por la anulación del voto. Los tres partidos mayores aseguraban que el voto nulo dañaba la democracia. ${ }^{10} \mathrm{El}$ ex gobernador de Jalisco y ex secretario de gobernación, Ramírez Acuña, acusó de ser unos cobardes a los que estaban promoviendo el voto nulo. El cardenal de Guadalajara se sumó a la descalificación e hizo un llamado a los católicos para que no hicieran caso a los que llamaban a anular el voto. ${ }^{11}$ El presidente del organismo electoral estatal jalisciense llegó a calificar de ilegal lo que hacían los diversos grupos favorables al voto nulo. En todo esto se desconocía que el ciudadano debía gozar de libertad ante las opciones electorales y que una de ellas era anular su voto.

A finales de mayo el IFE también reaccionó frente al movimiento anulista. Algunos consejeros lo acusaban de antidemocrático, de ser contrario a la consolidación de un sistema democrático. ${ }^{12}$ Estas consideraciones tajantes se fueron cambiando un poco, y a principios de junio el IFE consideró prudente promover un debate público para escuchar las opiniones de los promotores del voto nulo. ${ }^{13}$ No obstante, consejeros electorales cabildearon ante medios electrónicos para que no alentaran dicho voto. ${ }^{14}$ El IFE y los partidos intensificaron la promoción del voto partidista.

10. La Jornada, 10 de junio de 2009.

II. Mural, 22 de mayo de 2009.

12. La Jornada, 30 de mayo de 2009.

13. El Universal, 4 de junio de 2009.

14. La Jornada, 6 de junio de 2009.

\section{8}


La presidenta del Tribunal Electoral también arremetió en contra de los anulistas. Decía que, si los ciudadanos querían enviar un mensaje a los partidos, no debían anular el voto sino buscar otros espacios. ${ }^{15}$ Por su parte, la Comisión de Participación Ciudadana de la Cámara de Diputados se pronunció en contra de la campaña del voto nulo, y advirtió que ese sufragio fortalecería los cacicazgos. ${ }^{16}$

El episcopado mexicano consideró que la campaña por la anulación del voto era un retroceso, pidió que se suspendiera y anunció que impulsaría la participación en los comicios. ${ }^{17} \mathrm{El}$ investigador sobre la iglesia mexicana Bernardo Barranco señaló que la jerarquía había percibido que encarar el voto nulo podía congraciarla con el IFE y legitimar campos de actuación en los procesos electorales. Pero precisó que algunos miembros de esa jerarquía se habían enganchado en una lucha contra el voto nulo sin dirimir a fondo los entretelones de la controversia en la que había insatisfacción, hartazgo, pérdida de confianza, indignación por abusos e impunidades, y sin ver que los ciudadanos tenían la libertad de hacer uso de un recurso válido en las democracias modernas (Barranco, 2009).

El escritor Miguel Ángel Granados Chapa se manifestó contrario a la andanada de improperios que se lanzaba contra los anulistas (Granados, 2009a). El investigador Alberto Aziz preguntaba por qué tanto temor a que unos cuantos ciudadanos pudieran ejercer el derecho de participar desde la protesta (Aziz, 2009c). José Antonio Crespo preguntaba por qué a los partidos y sus defensores les preocupaba más el voto nulo que la abstención, pues los abstencionistas activos repudiaban tanto el sistema de partidos como el proceso electoral (Crespo, 2009e). El lema de

15. La Jornada, 12 de junio de 2009.

16. El Universal, 18 de junio de 2009.

17. Reforma, 3 de junio de 2009; El Universal, 8 de junio de 2009. 
los que estaban en contra del movimiento anulista diciendo "Yo sí voto por México" era excluyente y falso, porque los que libremente optaran por el voto nulo no estaban contra México (Granados, 2009b). El editorialista Eduardo Huchim apuntaba que las oligarquías partidistas se mostraban preocupadas porque había segmentos ciudadanos hartos del proceder de los partidos. Pese a que se argumentaba que no tendría ningún efecto ya había tenido el de haber concitado la atención pública (Huchim, 2009). El periodista Luis Hernández remarcó que el fantasma del voto nulo asustaba a la clase política mexicana. Destacó la emergencia de redes informáticas entre jóvenes urbanos que mostraban nuevas sensibilidades (Hernández, 2009). Con su reacción intolerante, los de arriba querían hacer aparecer lo que era algo legal como ilegal y subversivo, y hasta como un peligro para México (Crespo, 2009f). Sergio Aguayo resumió: los partidos, los cardenales, los obispos, Andrés Manuel López Obrador, Martha Sahagún y otros más habían calificado a los promotores del voto nulo de antidemocráticos, simplistas, irresponsables, demagogos, perversos e instrumentos de la derecha, etc. Pero lo que se estaba pidiendo no era incinerar a los partidos, sino exigirles eficiencia, austeridad, honestidad y una mejor oferta de candidatos (Aguayo, 2009b).

\section{La defensa de la legalidad y legitimidad del voto nulo}

Promotores del voto nulo se defendieron de los ataques, y argumentaron que ejercían un derecho y una libertad ciudadana y que lo hacían para promover un México democrático de verdad. ${ }^{18}$ A principios de junio el grupo jalisciense Anulo mi voto hizo un balance del desempeño del movimiento 
anulista. Se alegraba porque después de siete semanas de haber iniciado ese movimiento se había producido una deliberación en todo el país para hablar sobre democracia y no sobre candidatos. Volvía a precisar que anular el voto intencionalmente era un derecho ciudadano que se debía garantizar; que anular el voto emitiría un rechazo a los partidos y sus candidatos. Le sorprendía la reacción de políticos y líderes sociales de todos los colores e ideologías que le inventaban patrocinios. Eso mostraba que quienes lo atacaban pensaban que México era su botín, pero tenían al país dinamitado y sin proyecto viable. Este grupo proponía un proceso de deliberación nacional que permitiera diseñar una agenda de una Constituyente Pacífica 2010. En la lista de lo que habría que revisar estaban leyes de control social total de lo público; nueva gestión del territorio, del uso del suelo y del agua; eliminación de monopolios políticos y económicos; respeto a los derechos políticos, sociales, culturales y ambientales; educación y salud universal de calidad; ley de sindicatos; garantía a la seguridad pública con libertad; valor electoral a la anulación y abstención; nueva conformación de los poderes Legislativo, Ejecutivo y Judicial; revocación de mandato; candidaturas independientes; reelección de legisladores y alcaldes; mecanismos de planeación intermunicipales; aumento de capacidades vecinales; movilidad sustentable; servicio civil de carrera; y presupuestos participativos. ${ }^{19}$ Porfirio Muñoz Ledo también trató el debate sobre la anulación del voto. Recalcaba que el sistema electoral se había corrompido y que eran inocultables los vicios de la partidocracia y proponía una Asamblea Constituyente para 2010 (Muñoz, 2009). 


\section{Del rechazo a la escucha}

Aunque se había dicho que el voto nulo no servía para nada, finalmente el presidente del IFE tuvo que aceptar que la ley marcaba que si la cantidad de votos nulos era superior a la diferencia entre el primero y segundo lugar, en el cómputo distrital habría que abrir los paquetes electorales y contar voto por voto. ${ }^{20}$ Otro efecto jurídico que destacó José Antonio Crespo era que, si bien no afectaba el reparto en el financiamiento, si podía repercutir en el refrendo legal de algunos partido. Es decir, podría favorecer a los partidos grandes pero no a los chicos (Crespo, 2009g).

En Jalisco los consejeros de la junta local del IFE sostuvieron una reunión de discusión que se hizo pública en un periódico. Aceptaron que la anulación del voto era un mensaje claro del hartazgo hacia los partidos. ${ }^{21} \mathrm{El} 15$ de junio se realizó un foro promovido por el ITESO en el que participaron el presidente del organismo local electoral jalisciense, un miembro del Congreso Ciudadano promotor del voto nulo, y un periodista que defendía la abstención. El presidente del organismo electoral cambió de parecer y aceptó que el voto nulo era legítimo. Pero insistió en que no tenía implicación en el resultado final de la jornada electoral. Quien representaba la opinión de los anulistas dijo que era una oportunidad para expresar el descontento. El promotor de la abstención enfatizó que no había que votar porque en la vida laboral no había democracia, el sistema político era una mesa de tráfico de influencias, la corrupción

20. El Universal, 9 de junio de 2009. En las discusiones también se hacía ver que en otros países el voto nulo tenía consecuencias directas sobre el sistema de partidos. Había países en donde el financiamiento público se calculaba de acuerdo a cada voto válido, como era el caso de España, Chile y Argentina. En Colombia se podía repetir la elección a puestos del Ejecutivo si los votos nulos constituían mayoría absoluta en relación con los votos válidos. En Chile se diferenciaba el voto en blanco y el voto nulo.

21. La Jornada Jalisco, 10 de junio de 2009. 
continuaba, los candidatos eran elegidos por unos cuantos y los consejeros tenían altos sueldos, muy costosos para los ciudadanos. ${ }^{22}$

El IFE también aceptó que hubiera una mesa sobre el voto razonado el 18 de julio. Sergio Aguayo, José Antonio Crespo, Jorge Buendía, Leo Zuckermann, Federico Reyes Heroles y Denise Dresser hablaron a favor del voto nulo. Jorge Alcocer, Lorenzo Córdova, Jesús Silva Herzog Márquez y José Woldenberg ${ }^{23}$ se manifestaron a favor del voto. Hubo quienes señalaron que el voto nulo era un capricho de intelectuales que adoptaban una actitud tremendista. Se sintetizaron las posturas que se habían venido exponiendo en los medios escritos de comunicación. Ante la propuesta que hizo Reyes Heroles de que se hiciera una encuesta de salida para detectar las razones del voto de los electores, José Antonio Crespo manifestó que sería una buena medida pues resultaba difícil saber por qué se emitía un voto de protesta. Pero sugirió que también se indagaran las razones de los abstencionistas (Crespo, 2009h). Promotores del voto nulo que habían sido invitados, y luego "des-invitados" como ponentes, y que participaron desde las butacas, demandaron al IFE a difundir sus opciones de voto. Aprovecharon la sesión para afianzar contactos y para constituirse en un frente. Convocaron a una asamblea nacional para el 30 de junio. Entre los grupos más activos estaban los que se autodenominaban Anula tu Voto, Voto Independiente, Frente Democrático Ciudadano de Tlalpan, Propuesta Cívica Esperanza Marchita, Voto en Blanco, Yo Voto por Quien Quiera y Anulo mi Voto. ${ }^{24}$

22. Disponible en: www.iteso.mx, 16 de junio de 2009.

23. El IFE organizó este acto con ponencias de académicos y escritores que tenían columnas semanales en diarios de la Ciudad de México.

24. Reforma y El Universal I8 de junio de 2009. 


\section{Hacia la organización de los anulistas}

El 30 de junio se llevó a cabo en la Ciudad de México una Asamblea Nacional por el Voto Nulo en la que participaron 42 organizaciones y más de 300 ciudadanos. Los moderadores elegidos fueron Sergio Aguayo, dirigente de Propuesta Cívica, Elisa de Anda, representante de Vota Independiente, y Carlos Paéz, representante de Anulo mi Voto, agrupación de Guadalajara. Como Secretaria se eligió a Alma Rosa Garza del Colectivo de Saltillo. Cada organización fue exponiendo sus propuestas y se debatió qué temas agruparían las peticiones iniciales a la nueva legislatura federal. Se enfatizó que el movimiento por la anulación del voto pasaba de la protesta a la propuesta. Entre las propuestas acordadas estaba la de impulsar la democracia directa (referéndum, plebiscito e iniciativa popular), revocación de mandato, reglamentación del voto nulo, reducir las prerrogativas a los partidos, exigir rendición de cuentas y candidaturas independientes. La propuesta de la reelección de legisladores, presidentes municipales y gobernadores fue rechazada por falta de votos necesarios. En esta primera asamblea se habló de la necesidad de un nuevo nombre y se barajaron varios de los cuales la mayoría iniciaba con la palabra movimiento (Núñez, 2009). Los agrupamientos participantes optaron por conseguir recursos y contratar a una casa encuestadora para hacer una encuesta de salida para conocer las razones por las que los anulistas habían votado nulo. Se insistió en que el voto nulo no intenta acabar con la democracia sino mejorar su funcionamiento y su representatividad.

La encuesta pagada por los grupos anulistas, fue encargada a la empresa Parametría. A nivel nacional los votos nulos alcanzaron 5.4\%. De acuerdo con la encuesta, al menos $3 \%$ correspondió a una anulación intencional. 
Según la encuesta, 65\% de los votantes de las delegaciones del DF y $62 \%$ en municipios de Jalisco habían oído hablar de la campaña que promovía la anulación del voto. Entre los que optaron por anular su voto, $55 \%$ correspondía a los hombres y $45 \%$ a mujeres; $23 \%$ tenía entre los 18 y 25 años, $23 \%$ entre los 26 y $35,19 \%$ entre los 36 y $45,17 \%$ entre los 46 y 55 y $18 \%$ entre los 56 y más años. De ellos, $37 \%$ percibía entre uno a 7 salarios mínimos, y $43 \%$ recibía más de 7 salarios mínimos; $28 \%$ había cursado preparatoria y $51 \%$ tenía estudios universitarios. Además, 56\% desaprobaba la gestión de Calderón; 60\% no estaba de acuerdo con la gestión del gobernador de Jalisco o la del Jefe de Gobierno del DF; 73\% repudiaba la gestión de delegados y presidentes municipales. Dos terceras partes no se identificaba con ningún partido, aunque $12 \%$ se declaró panista, $7 \%$ perredista, $4 \%$ priista, y $6 \%$ de otros partidos. Cuatro quintas partes se pronunciaba por las candidaturas ciudadanas y $74 \%$ quería que hubiera revocación de mandato.

La segunda Asamblea Nacional Ciudadana se realizó en Guadalajara el 18 de julio de 2009 con la participación de 47 organizaciones de todo el país. Se efectuaron cuatro mesas de trabajo (sobre democracia participativa; reducción de presupuestos a partidos y rendición de cuentas; candidaturas independientes; y articulación ciudadana del movimiento). Se amplió la deliberación. Se volvió a debatir sobre la democracia directa en la que se incluyeron además los temas ya tratados en la primera asamblea, las consultas ciudadanas, consejos ciudadanos, asociaciones vecinales, comités ciudadanos, etc. En el examen sobre la democracia representativa se añadió la integración, facultades, funcionamiento y financiamiento del organismo electoral, regulación de partidos y segundas vueltas. Otro gran apartado de temas implicaba la rendición de cuentas, la transparencia, el derecho a la información, la contraloría social, las percepciones de los servidores públicos y el fuero. Hubo una fuerte 
discusión sobre si se debía llevar la iniciativa de los grupos al Congreso de la Unión. Finalmente ganó la propuesta de que habría que hacerlo.

Las propuestas y las tácticas en este movimiento se caracterizaban por tener mucha creatividad, innovación, originalidad, frescura, humor y originalidad. Sus integrantes aprendían con rapidez. Después de dos asambleas nacionales se formuló una propuesta de discusión y deliberación en torno a la metodología que sería más útil para las siguientes asambleas. Se hicieron ajustes en relación a su moderación, a las discusiones, al diálogo y a las votaciones. Se buscaba que se tomaran acuerdos de manera amable y efectiva (ANCA Jalisco, 2009).

El 15 de agosto sesionó la III Asamblea Nacional Ciudadana en Tlaxcala a la que acudieron 110 integrantes. Se había anunciado que asistirían Patricia Mercado y Sergio Aguayo, pero declinaron participar en esta asamblea. Se discutió un documento que había sido elaborado pluralmente por 15 impulsores de la nueva organización. El documento destacó que se habían generado encuentros de muchos ciudadanos, tanto en el espacio virtual como en las calles, en torno al voto nulo. Este documento enfatizaba lo relativo a la articulación de los integrantes de la asamblea para su operación interna y externa. Se quería trascender el momento electoral y darle continuidad al movimiento anulista. El movimiento se planteaba ser abierto, plural, horizontal, deliberativo, apartidista e independiente. Se recalcaba que el movimiento era ciudadano, y desde esa perspectiva se planteaba la relación con los poderes políticos establecidos. Se pretendía crear un espacio de articulación, deliberación y acción ciudadana que conservara y propiciara la pluralidad y el sentido abierto que caracterizaba a ese movimiento. También se proponía que el movimiento se convirtiera en un observatorio de lo público con el fin de generar debates en la agenda ciudadana. Para mantener la autonomía del 
movimiento no se recibiría ningún tipo de financiamiento de organismos públicos gubernamentales y descentralizados. Los anulistas querían encontrar mecanismos de evaluación y autocrítica. También querían crecer. Punto central de su preocupación era el diseño de mecanismos de coordinación y comunicación que garantizaran la horizontalidad del movimiento. Cada organización continuaría con su propio trabajo. Se aprobaron comisiones para enfrentar las tareas futuras. Se planteaba construir una página Web, una base de datos y un boletín de prensa. Se recalcaba que había que cuidar una operación dinámica en red. Se buscaba que la información fuera el pilar de la articulación del movimiento. Era necesario generar un directorio nacional, favorecer la discusión permanente, crear foros virtuales, etc. Para la comunicación habría que generar un portal de Internet, lograr presencia mediática de forma creativa, y generar medios de comunicación alternativos. Se destacaba que era una tarea ciudadana vigilar y supervisar a los poderes públicos. El movimiento ya había demandado cambios en las reglas que regían a los partidos y a las instituciones electorales. Exigirían a los legisladores que tomaran en cuenta las demandas de los ciudadanos y que se utilizaran los presupuestos públicos de manera honesta y transparente (Varios, 2009). De nueva cuenta se discutió lo relativo al nombre y se propuso una votación por Internet acerca de tres opciones entre las que estaban Asamblea Nacional Ciudadana, Movimiento Ciudadano y Voto Válido. Se nombraron comisiones para elaborar un documento declaratorio de cara a los ciudadanos; para organizar acciones en la fecha de la toma de protesta de los diputados y para aprovechar las fechas patrias para hacer saber que se estaba elaborando un inventario nacional y que se exigirían a los gobernantes resultados en las celebraciones del año 2010; también habría un comité de difusión que diera a conocer los fundamentos, principios rectores y acciones del movimiento. 
La acción del primero de septiembre se realizó con el nombre de Asamblea Nacional Ciudadana. Para esa fecha el movimiento ya había adquirido claridad sobre cómo presentarse y las acciones inmediatas a realizar. Se enfatizaba que la protesta del voto nulo había nacido del deseo de vivir en una comunidad justa, equitativa y solidaria. Después de tres reuniones nacionales, el movimiento había decidido ejercer su poder ciudadano para la transformación democrática de México. En su declaración hicieron ver que su descontento no se reducía al ámbito electoral. ${ }^{25}$ Decían que se habían activado porque les preocupaba la degradación de la calidad de vida, del patrimonio público, de los ecosistemas, de la disminución del bienestar, del aumento de la pobreza y la desigualdad. Querían una democracia con transparencia, rendición de cuentas, vigilancia social y participación ciudadana. Anunciaban que el movimiento proseguiría hasta que los poderes constituidos fueran elegidos con reglas verdaderamente democráticas y desapareciera la partidocracia. La ANCA instaló el primero de septiembre mesas discusión y debate público frente al Palacio Legislativo para que se exigiera al poder Legislativo que escuchara a los ciudadanos, y demandó que los diputados abrieran las deliberaciones en torno a las propuestas de instaurar mecanismos de democracia directa y que se le diera al voto nulo valor jurídico; también planteaban que se redujera el financiamiento a los partidos y que garantizaran la transparencia de sus actuaciones; exigían la instauración de candidaturas ciudadanas. El movimiento precisaba que esos eran puntos de partida mínimos, pero que muchas otras cosas tenían que cambiar (ANCA, 2009).

25. Firmaron la declaración de la ANCA 69 organizaciones de 20 estados de la República. Algunas de ellas se identificaban, además de ciudadanas, como de periodistas, abogados, consumidores, artistas, investigadores, empresarios, colonos, vecinos, mujeres, jóvenes, indígenas, militares, socialistas, etc. Había muchas que incluían en su nombre alguna referencia a la anulación del voto. 


\section{Los impactos del voto nulo}

Los votos nulos se colocaron en el quinto sitio de votación por encima del PT, Panal y Convergencia. En Puebla, San Luis Potosí y Campeche alcanzaron a ubicarse después de dos grandes partidos nacionales. En ocho estados ocuparon el cuarto lugar. En el Distrito Federal los votos nulos consiguieron 10.8\%, en Aguascalientes 8.1\%, en Chihuahua 7.4\%, en San Luis Potosí y en Puebla 7.3\%, en Michoacán 6.7\%, en Tlaxcala 6.6\%, en Baja California 6.3\%, En Quintana Roo 6\%. Jalisco se ubicó en el lugar 13 entre las entidades con más votos nulos.

José Antonio Crespo apuntó que funcionarios de casilla y funcionarios electorales habían aceptado que 80\% del voto nulo había sido de protesta. Precisó que el movimiento del voto nulo no fue propiamente nacional sino regional y urbano. En donde alcanzó más impacto fue en las ciudades de Morelia con $12.3 \%$, Puebla con $11.9 \%$, DF con $11 \%$, Chihuahua con 8.9\%, Aguascalientes con 8.8\%, Ciudad Juárez con $8.2 \%$, San Luis Potosí con $8.1 \%$ y Tijuana con $8 \%$. Este voto de protesta detuvo la tendencia creciente abstencionista (Crespo, 2009i). Siguió habiendo voto anulado por equivocación, por ejemplo al marcar coaliciones, pero fue el menor. Otro dato que resalta Crespo es la diferencia de participación en las entidades en donde hubo elecciones concurrentes para gobernador, pues en las seis entidades donde eso pasó la participación se elevó a un promedio de $57 \%$, mientras que en el resto de las entidades ese promedio estuvo en $42 \%$ (Crespo, 2009i).

Hubo quienes plantearon que el movimiento anulista no había conseguido buenos resultados. Argumentaban que el voto nulo en las elecciones intermedias de 2003 había llegado a 3.3\%, por lo que los anulistas de 2009 sólo le habían añadido dos puntos porcentuales. Consideraban que era "una fantasía" hablar de los anulistas como una fuerza 
electoral nacional. Sólo habían convencido a gente que tenía Internet, que es una proporción minoritaria en el país. Se había tratado de una protesta testimonial (Aguilar, 2009). Los anulistas se defendían de la crítica de ser un movimiento elitista que no tenía impacto popular, e insistían en que se trataba de un movimiento reformista y ubicado lejos del conservadurismo (Lajous, 2009). José Antonio Crespo, tenaz analista y defensor del voto nulo, hizo ver otro impacto político que había tenido dicho voto. Cuando tanto el PAN como el PRD rechazaron el criterio del IFE en la distribución de las diputaciones proporcionales, si bien antes habían aducido que el voto nulo no tenía ningún efecto político, en su alegato contra el IFE insistieron en que el voto nulo sí debía ser tenido en cuenta para la distribución de los diputados de representación proporcional (Crespo, 2009j). La investigadora Rossana Reguillo consideró que, desde una mirada cualitativa, el movimiento plural y diverso del voto nulo había sido un éxito pues había logrado mover la imaginación ciudadana hacia otras maneras de entender la política, y había transformado la experiencia electoral para impulsar nodos de presión política. Otro logro que apreciaba en ese movimiento es que había conseguido repolitizar a un buen número de jóvenes (Reguillo, 2009). Un impacto importante que tuvo el movimiento anulista fue que se logró constituir como movimiento nacional novedoso después de las elecciones.

\section{Revisión de las cifras oficiales del voto nulo}

El comportamiento del voto nulo de 1991 a 2009 se puede ver en la siguiente tabla. 


\section{Tabla 1}

Votos nulos en elecciones de diputados federales en México

$\begin{array}{llllllll}\text { Año } & 1991 & 1994 & 1997 & 2000 & 2003 & 2006 & 2009\end{array}$

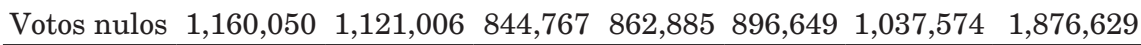

Fuente: IFE.

Las cifras de votos nulos en las primeras dos elecciones del IFE pueden estar indicando anulaciones provenientes de manipulaciones en el organismo electoral en contra de la oposición. Destaca el elevado número de votos nulos y sus altos porcentajes, pues en 1991 fue de $4.8 \%$ y en 1994 de $3.2 \%$. Con un IFE confiable, que surgió por la reforma de 1996, tenemos en las elecciones a cargo de su primer consejo general autónomo un voto nulo muy estable entre 1997 y 2003. En 2006 hubo un incremento debido a la polarización de ese proceso electoral, pero su porcentaje se situó entonces en $2.5 \%$. No obstante, tanto en números absolutos como relativos en 2009 hubo un incremento muy fuerte del voto anulado. En estos comicios el porcentaje de ese voto fue de $5.4 \%$. Porcentualmente el voto nulo a nivel nacional y en Jalisco en las últimas dos elecciones ha tenido un comportamiento bastante similar. En cifras absolutas, el voto nulo en las elecciones federales en Jalisco se ha dado como se puede apreciar en la siguiente tabla.

Tabla 2

Votos nulos en elecciones de diputados federales en Jalisco

\begin{tabular}{lccccccc} 
Año & 1991 & 1994 & 1997 & 2000 & 20003 & 2006 & 2009 \\
Votos nulos & 71,660 & 64,311 & 55,520 & 50,510 & 52,915 & 64,611 & 141,654 \\
\hline
\end{tabular}

Fuente: IFE.

Entre 1991 y 2006 la mayor cantidad de votos nulos se dio en la primera elección a cargo del IFE. Parecía que 
la tendencia iba a la baja en este tipo de voto; en 2006 se repitió la cifra alcanzada en 1994; pero en 2009 hubo un incremento de 119\% con relación a la elección anterior, y casi se duplicó el monto de votos nulos de 1991.

En las elecciones federales en Jalisco de 2009 el mayor porcentaje de votos nulos se situó en Zapopan con $7.4 \%$, seguido de Guadalajara con $6.4 \%$. Fue donde se concentró el voto nulo de la zona metropolitana. ${ }^{26}$ En Tlaquepaque fue de $5.2 \%$ y en Tonalá de $4.6 \%$. En Tlajomulco el voto nulo sólo alcanzó 4.5\%. Los distritos foráneos oscilaron entre 4.5\% (Ciudad Guzmán) y 3.6\% (el distrito del norte del estado). En todo el estado el voto nulo se situó en el quinto lugar de nueve opciones. En el distrito 8 alcanzó a ser la tercera fuerza, ${ }^{27}$ y se colocó en cuarto sitio en $42 \%$ de los distritos. Tanto en las elecciones federales como locales en el distrito 10 de Jalisco se expresó con mayor contundencia el voto nulo. En 135 casillas de las 408 instaladas en los comicios federales de este distrito el voto nulo fue del 10\% (Rocha, 2009). Los votos nulos en las elecciones de diputados locales en Jalisco se han manifestado de la siguiente forma.

Tabla 3

Votos nulos en las elecciones de diputados locales en Jalisco

\begin{tabular}{lccccccc} 
Año & 1992 & 1995 & 1997 & 2000 & 2003 & 2006 & 2009 \\
Votos nulos & 40,476 & 47,754 & 43,669 & 39,870 & 57,101 & 62,834 & 121,388 \\
\hline
\end{tabular}

Fuente: IEPC.

26. Fotos de José Bautista dan cuenta de la diversidad elegida por los anulistas. Se recurría a tradicionales insultos; se cruzaban todos los partidos; se decía que todos eran ratas; se ponía nulo, anulado o algún lema como "votos nulos para políticos nulos"; había quienes votaban por el perro Fidel; se ponía la expresión "basta"; $y$ había quienes especificaban el porqué de su rechazo: "a mí me violaron y la denuncia no procedió".

27. En este distrito los votos nulos superaron la votación del PRD con cinco puntos porcentuales. 
Hay muchas diferencias entre los votos nulos en las elecciones de diputados federales y en las de diputados locales. En el primer lustro de la década de 1990 las elecciones federales y locales fueron en años distintos. En el segundo lustro ambas fueron en el mismo año pero en mes diferente. En la primera década del siglo XXI las elecciones federales y locales han sido en la misma fecha. En las elecciones locales de 1992 hubo 31,184 menos votos nulos que en las federales del año anterior. En 1995 hubo 16,557 votos nulos menos en las elecciones locales que en las federales de 1994. En las elecciones locales de 1997 realizadas a finales de ese año hubo 11,851 votos nulos menos que en las federales de medio año. En las elecciones locales de 2000 hubo 10,640 votos nulos menos que en las federales de julio de ese año. En las elecciones de 2006 hubo 1,777 votos nulos menos en las locales que en las federales, pero tres años atrás hubo 4,186 votos nulos más en las locales que en las federales. En las elecciones locales de 2009, pese a haber sido concomitantes, hubo 7,138 votos más que en las federales; no obstante hubo 20,266 votos nulos menos, por lo que el porcentaje fue también menor pues sólo llegó a $4.5 \%$. Es decir, hubo ciudadanos que inutilizaron su voto en las elecciones federales, pero lo aprovecharon en las locales. Comparando los distritos en los comicios locales del distrito 10 hubo 4,202 votos nulos más que en el correspondiente distrito federal porque tuvieron contornos diferentes.

\section{Reflexiones sobre el voto nulo}

Hay un minoritario voto nulo que corresponde a equivocaciones de los votantes. Desde hace tiempo se ha expresado un voto nulo de rechazo a partidos y candidatos. El incremento del voto nulo se ha dado por la inconformidad de una parte de los votantes con el desempeño de los partidos y por los agravios de una creciente partidocracia. Pero en 2009 surgió un movimiento que le dio identidad, organici- 
dad y fuerza. Una importante pregunta es si en realidad se puede hablar de un movimiento anulista. No habría que olvidar que existe una gran variedad de planteamientos en torno al estudio de los movimientos sociales. Una vertiente los considera como procesos y redes de organizaciones, secuencias de acción basadas en redes sociales internas y marcos de acción colectiva que desarrollan la capacidad para mantener desafíos frente a oponentes poderosos. Se plantea que la acción colectiva puede adoptar muchas formas (breve o mantenida, institucionalizada o subversiva). Hay formas colectivas que surgen de conexiones informales que utilizan formas de acción ya conocidas y les introducen innovaciones. Desde esta óptica, la acción de los anulistas en 2009 puede ser ubicada como un movimiento novedoso, aunque acotado (Alonso, 2009). Primero fueron movimientos locales que después se constituyeron en un movimiento nacional. Antes el voto nulo era la expresión individual del descontento, y en 2009 se conformó un "nosotros" que le dio sentido y contundencia a esa forma de ejercer el voto. $\mathrm{Al}$ encontrar varios ciudadanos una expresión de repudio motivada y reflexionada, se propició que disminuyera el abstencionismo. Un elemento importante del movimiento anulista fue que estuvo conformado mayoritariamente por jóvenes citadinos de capas medias y altas, con alto nivel de escolaridad, quienes han innovado con mucha imaginación el repertorio táctico de los movimientos. Hubo un momento en que los anulistas dialogaron con personalidades académicas y mediáticas en el proceso de su conformación como movimiento nacional, pero después se han movido con mucha independencia de esas personalidades. No pocos de los anulistas se presentaron por primera vez ante las urnas y se iniciaron expresando su repudio a la clase política. ${ }^{28}$

28. Estos datos los proporcionó la investigadora Rossana Reguillo en un acto académico en el ITESO el 26 de agosto de 2009. La doctora Reguillo conoce desde dentro este movimiento. 
Habría que resaltar que los anulistas creían en el sistema electoral y utilizaban el voto para expresar lo que criticaban y apuntar aquello a lo que aspiraban. No era un voto homogéneo. Pero la homogeneidad no se da ni el voto partidista, pues aun en éste hay una gran gama de motivaciones y expectativas. En el voto nulo la amalgama era el rechazo. En las propuestas había una gran diversidad, aunque se logró conformar una serie de demandas discutidas que no se reducían a cambios en los partidos y el sistema electoral, sino que apuntaban hacia la reforma del Estado. No obstante, dicho voto no alcanzó la magnitud para poder empujar por sí mismo la agenda que se había propuesto. Venía a ser una llamada de atención a las élites para ser aprovechada por un conjunto de fuerzas convergentes que tuvieran la capacidad de impulsar un cambio democratizador. Pero también habría que reconocer que se expresaba entre muchas confusiones. Dado que en el poder fáctico de los medios de comunicación se quiso aprovechar para echar atrás la tímida independencia de los partidos respecto de la sujeción y los chantajes de dicho poder en los procesos electorales conseguida en la reforma de 2007, en las demandas que se lograron consensuar por los diversos grupos anulistas que entablaron un diálogo entre sí, nunca se propuso el acotamiento de los medios electrónicos como poder fáctico. ${ }^{29}$ Los grupos anulistas quedaron expuestos -más que los partidos-a los chantajes y manipulaciones de dicho poder fáctico. El movimiento anulista vio más como un aliado a ese poder en su propuesta de la anulación del voto como presión a los partidos que como un gran impedi-

29. Si bien en su declaración del primero de septiembre de 2009 este movimiento planteaba que querían evitar que la clase política siguiera privilegiando en sus decisiones a los poderes de la economía y de los medios de comunicación masiva, en sus demandas y propuestas no había planteamientos directos de acción sobre los mismos poderes fácticos. 
mento de la democracia. Cualquier reforma que no toque a los poderes fácticos será tergiversada. ${ }^{30}$

\section{Los números de la abstención}

Junto al voto nulo estuvo también una abultada abstención. Así como hubo encuestas para indagar lo que sucedió con el voto nulo, también se exploró el abstencionismo en 2009. La empresa encuestadora Gea-Isa hizo entrevistas a los votantes a la salida de las casillas y entrevistas después del cierre de casillas. Detectó que más de dos quintas partes de los abstencionistas expresaron rechazo a la política y a las elecciones: $19 \%$ dijo que no había ido a votar porque no tuvo tiempo, $14 \%$ porque no encontró la credencial, $10 \%$ por rechazo a partidos, $9 \%$ porque no sirven las elecciones, $14 \%$ porque no le interesa votar, $8 \%$ porque no acostumbra hacerlo, $12 \%$ por algún otro problema, y $3 \%$ por olvido; $44 \%$ de los abstencionistas tienen entre 25 y 39 años, $25 \%$ entre 40 y 54, $19 \%$ entre 18 y 24 y $12 \%$ son de 55 o más años. El 30\% de los abstencionistas tienen educación media superior, 34\% tiene educación media básica, 25\% sólo la primaria, pero $11 \%$ posee educación superior. La mayoría de los abstencionistas trabaja, $26 \%$ corresponde a amas de casa, $11 \%$ a estudiantes y sólo $6 \%$ son desempleados. El $54 \%$ pertenece a algún sindicato, $43 \%$ tiene ligas con algún partido. El 23.4\% de los que acostumbran abstenerse dijo que se había decidido por el voto nulo. El $27.4 \%$ de los que se inclinaban por el PRI finalmente se abstuvo; 23.4 proclives al panismo no fueron a las urnas; 13.6 que votaría PRD no

30. Los poderes fácticos son aquéllos que no han sido elegidos por los ciudadanos (y que por lo tanto no les rinden cuentas). Sin embargo, determinan —en función de sus propios intereses - la vida colectiva que les atañe a todos. Suelen estar por encima y supeditando a los poderes oficiales jurídicamente constituidos como son el Ejecutivo, el Legislativo y el Judicial, los cuales de hecho se les someten. Los poderes constituidos jurídicamente no responden realmente a los ciudadanos, sino a los poderes fácticos. Éstos últimos impiden que funcione la democracia. 
acudió a votar. De todos los entrevistados, 86\% dijeron estar impactados por la crisis, $70 \%$ por la inseguridad y $42 \%$ por el narcotráfico. En todos estos casos la mitad votó y la otra mitad se abstuvo. ${ }^{31}$ Desde 1991 hasta 2009 la abstención nacional se ha comportado de la siguiente forma:

En el primer quinquenio de los años noventa, los abstencionistas eran una buena cantidad pero se encontraban por debajo de los que ejercían el voto. En el segundo quinquenio de esa década, se incrementaron tanto en números absolutos como relativos. En 2003 fueron muchos más los abstencionistas que los votantes. En 2006 los que no acudieron a votar porcentualmente igualaron a los de 1997. Entre 2003 y 2009 hubo 5'612,855 nuevos abstencionistas, lo que equivale a $13 \%$ de los abstencionistas de la última elección de la primera década del siglo XXI. En 2009, de nueva cuenta los abstencionistas superaron a los que sí acudieron a las urnas. Si a ellos se agregan los que usaron las urnas para expresar su rechazo a la clase política, tenemos que seis de cada diez ciudadanos - pese a las enormes sumas destinadas a las campañas y millones de spots con que fueron abrumados - no quisieron avalar a los partidos.

En Jalisco la participación electoral en las elecciones federales ha sido siempre mayoritaria por lo que la abstención, aunque ha crecido, se ha mantenido por abajo de 50\%, como se puede apreciar en la siguiente tabla.

En cada trienio estuvo por debajo de la abstención nacional varios puntos: 2.7 en la primera elección a cargo del IFE; 6.2 en 1994; 6.7 en 1997; 4.3 en 2000; 2.4 en 2006 y $6.7 \%$ en 2009. En la elección en donde obtuvo la distancia mayor fue en 2003, cuando la abstención en Jalisco fue 12.6 puntos por abajo del promedio nacional. No obstante, hay una importante diferencia. Mientras a escala nacional porcentualmente la abstención de 2009 es 2.9 puntos inferior

3I. Gea-Isa, Encuesta nacional simultánea a las elecciones federales del 5 de julio de 2009. Informe de resultados, julio de 2009. 


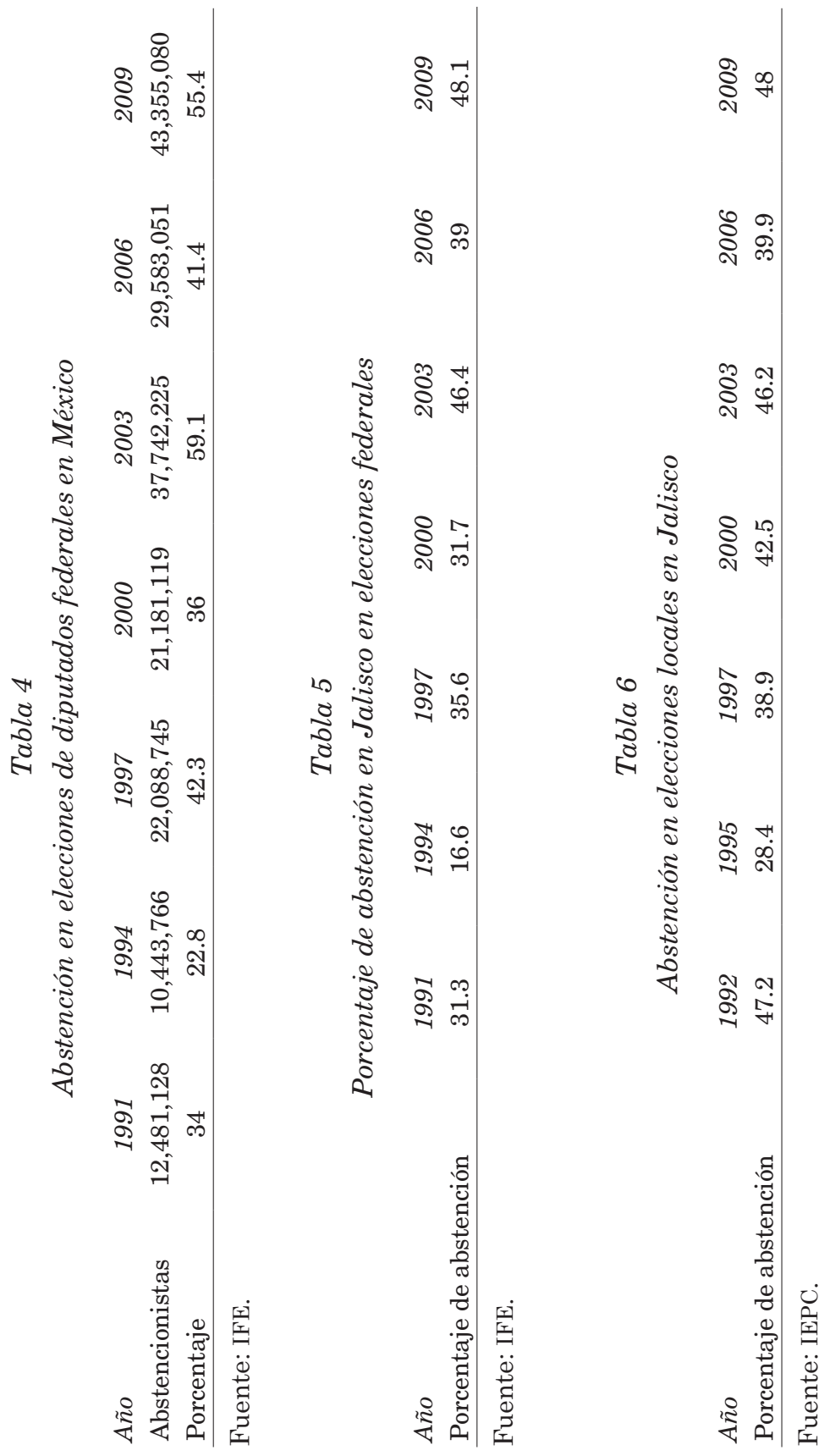


a la de 2003, en Jalisco la abstención de 2009 es 2.5 puntos superior a la de 2003. La abstención en las elecciones locales también ha tenido variaciones.

En los años noventa hubo más abstención en las elecciones locales que en las federales de Jalisco: 15.9 puntos más en 1992; 11.8 en 1995 y 3.3 en 1997. En las elecciones locales de 2000 la abstención fue 10.8 puntos más que en las federales. En 2003, cuando se iniciaron las elecciones concurrentes en Jalisco, la abstención en los comicios locales y federales en el estado fue similar, lo que se mantuvo en los dos siguientes comicios conjuntos. La abstención de 2009 fue superior a la de todos los comicios locales desde 1992 y superó casi por dos puntos la de 2003. Si se le suman los votos nulos, la mayoría de los electores jaliscienses, activa o pasivamente, se puso al margen de los partidos. ${ }^{32}$

\section{Reflexiones en torno a la abstención}

Las legislaciones electorales están diseñadas para desechar lo que implica la abstención, y todos los cálculos de reparto de puestos y de recursos públicos a los partidos contemplan votaciones ajustadas a ciertas fórmulas que benefician a los partidos. El mensaje de la abstención se desdeña desde el poder constituido. Si se considerara lo que obtienen los partidos en relación con todos los ciudadanos, se vería que los partidos ganadores apenas alcanzan una proporción muy minoritaria. Se habla de mayoría relativa, pero una comparación con el universo de votantes arroja que lo relativo es muy grande y que la mayoría es una minoría. Por ejemplo, en las elecciones federales de 2009 el partido que obtuvo más votos apenas obtuvo el aval de

32. Habría que precisar que todos los porcentajes acerca de la abstención sólo tienen en cuenta a los ciudadanos que se encuentran en el listado nominal. Si se consideraran todos los ciudadanos empadronados y los que, por algún motivo, no están todavía en el padrón, los números de la abstención aumentarían. 
15\% de los ciudadanos mexicanos. Una reflexión sobre este hecho debería llevar a considerar la escasa legitimidad de quienes usufructúan lo electoral.

Se han realizado varios estudios acerca de la abstención. En el Instituto Federal Electoral después de las elecciones de 2003 se abrieron paquetes electorales para hacer una investigación sobre los electores y los abstencionistas. Se detectó que los jóvenes asisten menos a las urnas que la población de mayor edad, y que en regiones no urbanas se vota menos. Las entidades con mayor abstención eran Baja California, Chiapas, Quintana Roo, Guerrero, Coahuila, Tlaxcala, Michoacán y Chihuahua. Los estados con menor abstención fueron Campeche y Querétaro. Jalisco se encontraba con 12.7 puntos abajo de la media nacional de abstencionismo. El 69.3\% de jóvenes de entre 20 y 24 años y $69.2 \%$ de los comprendidos entre los 25 y 29 años no votaron. Una aproximación al voto según sexo nos da que $73 \%$ de los hombres de entre 20y 24 años, y 72.9\% de hombres entre 25 y 29 años fueron abstencionistas (IFE, 2004). La firma Indicadores SC también realizó una indagación sobre las abstenciones en elecciones intermedias. Constató que quienes más votaban eran las capas más pobres, pues tenían expectativas que su voto redituara algo para remediar sus necesidades. ${ }^{33}$ Existen otras investigaciones que muestran el alto grado de manipulación de las élites en los procesos electorales (Wolin, 2008). Lo que se puede percibir es que tanto una buena porción de los abstencionistas y de quienes en 2009 anularon conscientemente su voto no se dejaron seducir por las manipulaciones partidistas. Los abstencionistas y los anulistas conforman una gran mayoría de ciu-

33. Elías Aguilar, de la Universidad de las Américas, participó en 2007 con la empresa Indicadores SC (que se presenta como un monitor de opinión pública sobre temas de coyuntura de interés público) con el texto "Las razones del abstencionismo en las elecciones intermedias en México", que se puede consultar en: ww.tvaztecapuebla.com.mx. 
dadanos a los que el sistema político no los tiene contentos ni los convence. Mientras los anulistas eran un grito de rechazo y de propuesta para reformar la política, no pocos de los abstencionistas buscaban en el silencio otras formas de hacer política.

Teóricamente se ha discutido lo que implica la no participación electoral. Huntington escribió que la operación eficiente de un sistema político requiere cierto grado de apatía y falta de compromiso por parte de algunos individuos y grupos (Huntington, 1976). En la abstención también se expresa una inmensa gama de actitudes. Las hay de desidia, de apatía, de silencio aprobante, pero también se ha venido manifestando un repudio al sistema político. El crecimiento de los abstencionistas en escenarios de gran gasto partidista para promocionarse e institucional de aliento del voto es una muestra del fracaso de los partidos y de los organismos electorales.

Por su parte, Sheldon Wolin, estudioso de la democracia estadounidense, dice que la apatía de los votantes es consecuencia de las bajas expectativas de que el gobierno responda a sus necesidades. Las élites no quieren un demos activo sino un votante ocasional. Mientras los técnicos políticos ven con agrado la apatía, quienes abogan por la democracia ven la baja participación electoral como una señal de alarma. La apatía está relacionada con el hecho de que muchos ciudadanos perciben la política como algo adaptado a las necesidades del poder. Existe un malestar creciente entre los ciudadanos por el rumbo de la política y no hay confiabilidad en lo electoral. La democracia no se ha enraizado y elementos clave de la misma han sido vulnerados. Varios de sus funcionamientos se han pervertido con fines antidemocráticos. Las elecciones deberían ser la condición del poder democrático, pero el pueblo no tiene control sobre el proceso mismo. Hay una paradoja. Mientras se considera que el demos tiene la autoridad para elegir, 
de hecho carece de poder efectivo para controlar o fijar los términos de las elecciones reales (Wolin, 2008). En el abstencionismo es posible ver una resistencia pasiva frente al poder. Pero no sólo eso, hay también cierta actividad. El especialista en cuestiones electorales, Pierre Rosanvallon ha señalado que si los ciudadanos frecuentan menos las urnas no es porque se hayan hecho pasivos. Hay ciudadanos que desconfían de los gobernantes y de las instituciones democráticas. Hay así una democracia reactiva, no institucionalizada. La decepción puede llevar al inmovilismo, o a otro tipo de movilización y búsqueda. Lo importante es que la desconfianza también ha sido vista como una virtud cívica, y no como una falta de la misma. Esos ciudadanos que no van a las urnas encuentran otras formas de participación (Rosanvallon, 2007). Cada vez más ciudadanos se ponen al margen de lo electoral. Va creciendo una resistencia al sistema político en su conjunto. Al ponerse al margen muchos ciudadanos se erosiona la legitimidad vigente y se dan indicios de búsquedas de convivencias en otras lógicas. Entre los abstencionistas se pueden detectar espacios de insubordinación y hasta de creación libre de espacios autónomos (Gutiérrez, 2006).8

Fecha de recepción: 24 de agosto de 2009. Fecha de aceptación: 22 de septiembre de 2009.

Bibliografía John Ackerman (2009a), "Abstencionismo y movimiento social”, La Jornada, I de junio.

(2009b), "Nulidad conformista", La Jornada, 29 de junio.

Aguayo, Sergio (2009a), "Por Esperanza”, en Reforma, 3 de junio.

(2009b), “Los 'suicidas”, Reforma, 10 de junio. 
Aguilar, José Antonio (2009), "Voto nulo: protesta metafíBibliografía sica”, Nexos, agosto. Disponible en: www.nexos.com. $\mathrm{mx}$.

Alonso, Jorge (2009, en prensa), Aproximaciones a los movimientos sociales.

ANCA (2009), Declaración de la Asamblea Nacional Ciudadana, documento, $I^{\circ}$ de septiembre.

ANCA Jalisco (2009), Metodología para las asambleas de la ANCA. Propuesta de discusión/deliberación, documento, 10 de agosto.

Anduiza, Eva (1999), ¿Individuos o sistemas? (Las razones de la abstención en Europa occidental), Madrid, Centro de Investigación Sociológica.

Ansaldi, Waldo (dir.) (2006), La democracia en América Latina, un barco a la deriva, México, FCE.

Asamblea Nacional por el Voto Nulo (2009), Boletín de prensa, 30 de junio.

Aziz, Alberto (2009a), "Votar, abstenerse o anular", El Universal, 2 de junio.

_ (2009b), Alberto Aziz, "Legitimidad anulada", en El Universal, 16 de junio de 2009.

— (2009c), "El voto, fortalezas y limitaciones", El Universal, 9 de junio.

Barranco, Bernardo (2009), "La Iglesia frente al voto nulo", La Jornada, 10 de junio.

_ (2009b), “Legitimidad anulada”, en El Universal, 16 de junio de 2009.

Basset, Yan (2003), "Abstención y voto negativo: de la interpretación sociológica a la lógica política”, en Isidro Cheresky y J.M. Balanguer (comps.), De la ilusión reformista al descontento ciudadano, Rosario, Homo Sapiens.

Bazdresch, Miguel (2009), "Voto ineficaz", Público, I5 de marzo. 
Bibliografía Comité Conciudadano para la Reforma Electoral (2009). Disponible en: www.comiteconciudadano.org. Fecha de consulta: $I^{\circ}$ de julio de 2009.

Corral, Javier (2009), "Frente al voto nulo", El Universal, 9 de junio.

Crespo, José Antonio (2009a), "Razones para no votar", Excélsior, 16 de febrero.

- (2009b), "Para políticos nulos... un voto nulo", Excélsior, 18 de mayo.

— (2009c), "Para abatir la abstención", Excélsior, I de junio.

— (2009d), "Masoquismo electoral”, Excélsior, 8 de junio.

- (2009e), “Abstencionistas vs. Anulistas”, Excélsior, 24 de junio.

—_ (2009f), “Voto nulo: 'un peligro para México”', Excélsior, 10 de junio.

— (2009g), "Voto nulo: efectos jurídicos", Excélsior, 15 de junio de 2009.

— (2009h), "Establecer el descontento", Excélsior, 19 de junio.

— (2099i), “Abstención y voto nulo”, Excélsior, 13 de julio.

— (2009j), "Proporcionalidad legislativa”, Excélsior, 28 de agosto.

García, Jorge (2003), Participación y abstención electoral: Consideraciones en torno al capital cívico, México, SOMEE.

Gil, Roberto (2009), “La agenda del voto en blanco”. Disponible en: www.exoline.com.mx. Fecha de consulta: I5 de junio de 2009.

Gómez Hermosillo, Rogelio (2009), "Para no anularnos", El Universal, 19 de junio.

Granados Chapa, Miguel Ángel (2009a), "Dilemas del voto”, Reforma, 8 de junio. 
_ (2009b), “Libertad de sufragio”, Reforma, II de Bibliografía junio.

Gutiérrez, Raquel (2006), ¡A desordenar! Por una historia abierta de la lucha social, México, CEAM.

Hernández, Luis (2009), "El fantasma del voto nulo", La Jornada, 9 de junio.

Huchim, Eduardo (2009), "Los bueyes como razón", Reforma, 9 de junio.

Huntington, Samuel (1976), "The democratic distemper", en Nathan Glazer e Irving Kristol, The American Commonwealth, Nueva York, Basic Books, pp. 9-38.

Instituto Federal Electoral (2004), Informe de resultados del estudio de la participación ciudadana en las elecciones federales de 2003, México, IFE.

Islas, Octavio (2009), “Movimiento social en la Web?”, Revista Mexicana de Comunicación, núm. I I7, julio-agosto, Pp. 39-40.

Justel, Manuel (200I), La abstención electoral en España 1977-1993: factores individuales y de contexto, Madrid, Universidad Complutense.

Lajous, Andrés (2009), "La metafísica elitista de la opinión pública y el capital social”. Comentario a la versión electrónica del artículo de José Antonio Aguilar de Nexos de agosto. Disponible en: www.nexos.com.mx.

Meyer, Lorenzo (2009), "El voto sin partido o cómo usar la crisis", Reforma, II de junio.

Montaño, J. G. (2004), El malestar de la democracia en México, México, Plaza y Valdés.

Montero, José Ramón ( I98I), "Una nota introductoria sobre los tipos de abstención y la movilidad de los abstencionsitas”, Estudis Electorals, núm. 7, pp. 73-93.

Muñoz Ledo, Porfirio (2009), “Anular o revocar”, El Universal, 19 de junio.

Narro, Jorge (2009), Diez consideraciones respecto al voto nulo, mímeo, Guadalajara. 
Bibliografía
Núñez, Gloria (2009), "Comentario de la Asamblea Nacional por el Voto Nulo”. Disponible en: www.webforo. com.

Olvera, Alberto (2009), "Voto nulo y activación conservadora", El Universal, 19 de junio.

Reguillo, Rossana (2009), El voto nulo no es un resultado, es un comienzo, documento, julio.

Riba, Lara (1995), Voto dual y abstención diferencial, Barcelona, tesis doctoral, Universidad Autónoma de Barcelona.

Rocha, Jorge (en prensa), “Lo que nos dejó el 5 de julio de 2009", Christus.

—_ (2009), "Qué pasó en el Distrito Electoral Federal 10 de Jalisco", La Jornada Jalisco, 17 de julio.

Rodríguez, Octavio (2009), "Votación europea, ¿una lección para México?”, La Jornada, II de junio.

Rosanvallon, Pierre, La contre-démocratie, París, Seuil.

Sánchez, Adolfo (2009), “¡Voto nulo?”, La Jornada, II de junio.

Torre, Juan Carlos (2003), "Los huérfanos de la política de partidos", en Desarrollo Económico, vol. 42, núm. I68, enero-marzo.

Varios (2009), Documento Articulatorio ANCA, II Asamblea Nacional Ciudadana, Tlaxcala, 15 de agosto.

Vicencio, Felipe (2009), “Abstenerse o votar", La Jornada Jalisco, 27 de abril.

Wolin, Sheldon (2008), Democracia SA. Democracia dirigida y el fantasma del totalitarismo invertido, Buenos Aires, Katz Editores. 